\title{
ANALISIS PENGARUH LETAK BAHAN TERHADAP DEFLEKSI BALOK SEGI EMPAT DENGAN TUMPUAN ENGSEL - ROLL - ROLL
}

\author{
Jahirwan Ut Jasron \\ Universitas Nusa Cendana, Jl.Adisucipto Penfui Kupang-NTT \\ Telp.(0380) 881590 \\ E-mail: jasron_unc@ymail.com
}

\begin{abstract}
Deflection is one of criteria in designing a construction. Analysis can be conducted by using several method and to obtain the more accurate result the process can be conducted by using a computer program. For comparison to evaluate the accurate of the analysis, a deflection test was conducted with a deflection test device. The exact analysis was conducted by using the three moment methods. The aim of this study is to analyze the effect of the lay out of load along the beam towards deflection. The deflection along the beam varied according on the load and its position. The deflection obtained for brass is $1,29 \times 10^{-3} \mathrm{~m}$, while for alluminium and steel are $1,25 \times 10^{-3} \mathrm{~m}$ and $4,87 \times 10^{-4} \mathrm{~m}$, respectively.
\end{abstract}

Keywords: Deflection, three moment methods, load

\section{PENDAHULUAN}

Pembebanan pada suatu batang atau balok yang ditumpu pada ujung-ujungnya menyebabkan sumbu batang atau balok mengalami lenturan. Lenturan ini membentuk suatu kurva dan disebut kurva defleksi [1]. Akibat lainnya dari pembebanan ini, pada setiap penampang batang atau balok akan terjadi tegangan lentur dan tegangan geser. Deformasi yang terjadi besarnya tergantung pada bentuk penampang lintang batang dan sifat mekanis bahan.Defleksi dan tegangan ini merupakan salah satu kriteria dalam mendisain suatu konstruksi. Amannya suatu konstruksi harus memenuhi persyaratan batas nilai defleksi. Dalam aplikasi, besarnya defleksi yang terjadi akibat pembebanan harus kecil yang artinya kelengkungan kurva defleksi hampir mendatar. Dan tegangan yang terjadi harus kecil dari tegangan yang diisinkan untuk bahan yang digunakan. Hal ini berlaku untuk kondisi statis maupun kondisi dinamis. Untuk kondisi dinamis misalnya pada poros atau rotor suatu konstruksi mesin dimana putaran kritis yang terjadi tergantung pada nilai defleksi maksimum yang diperoleh. Semakin kecil defleksi akan semakin besar putaran kritis dan berlaku sebaliknya. Kerusakan (patah) suatu poros atau rotor akan terjaddi apabila putaran kritis berimpit dengan putaran normalnya (frekuensi pribadi sistem sama dengan frekuensi gaya luar), sehingga akan menyebabkan defleksi yang terjadi adalah amat besar, kondisi ini harus dihindari. Dalam menganalisis balok maka balok akan dibedakan atas dua jenis yaitu balok statis tertentu apabila dapat diperoleh semua reaksi, gaya geser, momen lentur dari diagram benda bebas dan persamaan kesetimbangan dan balok statis tak tentu apabila banyaknya reaksi melebihi banyaknya persamaan kesetimbangan independen [2]. Jenis dan banyaknya tumpuan pada sepanjang balok akan sangat mempengaruhi analisis dari balok tersebut. Apabila suatu balok adalah statis tak tentu, maka persamaan kesetimbangan tidak cukup dan dibutuhkan persamaan tambahan lain. Metode paling mendasar untuk menganalisis balok statis tak tentu adalah dengan memecahkan persamaan diferensial kurva defleksi. Hampir semua jenis struktur yang dijumpai sehari hari seperti rangka mobil, gedung, pipa-pipa, dan pesawat terbang adalah statis tak tentu. Namun struktur seperti itu lebih rumit daripada balok dan harus didesain dengan menggunakan cara-cara analitis yang sangat canggih. Namun demikian banyak di antara cara-cara tersebut yang didasarkan atas dasar analisis balok.

Analisis dimulai dengan melepas redundan dan mendapatkan struktur primer (struktur terlepas), sehingga diperoleh struktur primer dalam bentuk balok-balok sederhana. Setiap balok sederhana mengalami dua 
pembebanan: (1) beban luar yang bekerja dimasing-masing balok menerus, dan (2) momen redundan yang bekerja di ujung-ujung balok sederhana. Semua beban ini menghasilkan sedut rotasi di ujung-ujung setiap balok sederhana. Persamaan keserasian menyatakan bahwa di setiap tumpuan pada dua balok yang bersebelahan harus mempunyai sudut rotasi sama. Dengan memecahkan semua persamaan keserasian tersebut didapatkan semua momen lentur redundan.

Pada Gambar 1 diperlihatkan bahwa balok memiliki tiga tumpuan berturut-turut yang diidentifikasikan sebagai tumpuan $\mathrm{A}, \mathrm{B}$, dan $\mathrm{C}$. Bentang Balok di kanan tumpuan $A$ mempunyai panjang $L$ dan momen inersia $I$, demikian juga dengan bentang di kanan tumpuan B. Kalau struktur tersebut dibagi menjadi balok-balok sederhana maka akan diperoleh struktur primer seperti pada gambar berikut [3].
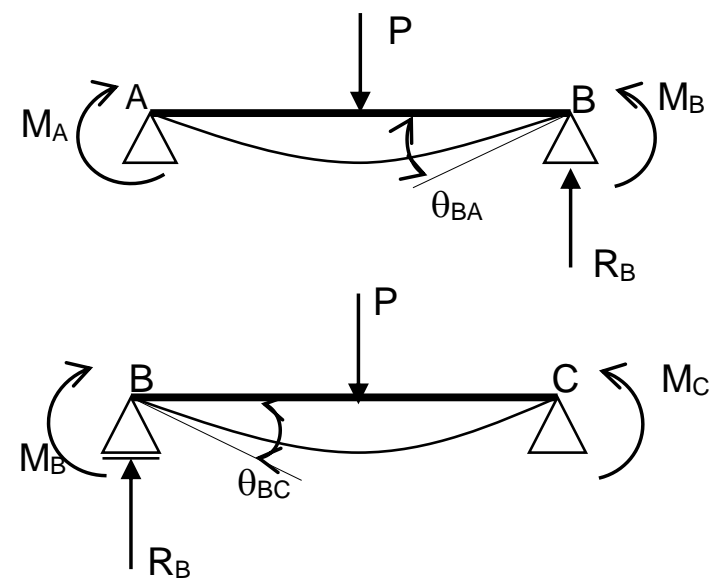

Gambar 1. Konfigurasi struktur balok

Persamaan keserasian di titik $B$ adalah:

$$
\theta_{B A}=-\theta_{B C}
$$

Masing-masing sudut tersebut sama dengan superposisi dari dua sudut: (1) sudut rotasi dibalok sederhana akibat beban luar, dan (2) sudut rotasi di balok sederhana akibat momen lentur anu. Kedua sudut rotasi dapat dicari dengan persamaan:

$$
\left(\theta_{B A}\right)_{2}=\frac{M_{A} \cdot L}{6 E I}+\frac{M_{B} \cdot L}{3 E I}
$$

$$
\left(\theta_{B C}\right)_{2}=\frac{M_{B} \cdot L}{3 E I}+\frac{M_{C} \cdot L}{6 E I}
$$

Sudut rotasi akibat beban luar dan momen lentur diperoleh dengan superposisi sebagai berikut:

$$
\begin{aligned}
& \theta_{B A}=\left(\theta_{B A}\right)_{1}+\left(\theta_{B A}\right)_{2}=\left(\theta_{B A}\right)_{1}+ \\
& \frac{M_{A} \cdot L}{6 E I}+\frac{M_{B} \cdot L}{3 E I} \\
& \left(\theta_{B C}\right)=\left(\theta_{B C}\right)_{1}+\left(\theta_{B C}\right)_{2}=\left(\theta_{B C}\right)_{1}+ \\
& \frac{M_{B} \cdot L}{3 E I}+\frac{M_{C} \cdot L}{6 E I}
\end{aligned}
$$

Kedua persamaan tersebut memberikan sudut rotasi di struktur primer di tumpuan B yang kemudian dimasukkan ke dalam persamaan keserasian sehingga diperoleh persamaan berikut:

$M_{A}+4 M_{B}+M_{C}=-\frac{6 E I}{L}\left(\theta_{B A}\right)_{1}-\frac{6 E I}{L}\left(\theta_{B C}\right)_{1}$

Dalam melakukan perhitungan dengan persamaan tiga momen, sudut $\left(\theta_{B A}\right)_{1}$ dan $\left(\theta_{B C}\right)_{1}$ harus dinyatakan dalam radian.

\section{METODOLOGI PENELITIAN}

Dimensi spesimen uji defleksi masingmasing jenis material adalah : Batang segi empat dengan panjang $1000 \mathrm{~mm}$, tinggi $8 \mathrm{~mm}$ dan lebar $12 \mathrm{~mm}$. Dimensi spesimen uji tarik disesuaikan dengan spesifikasi mesin uji tarik yang digunakan.
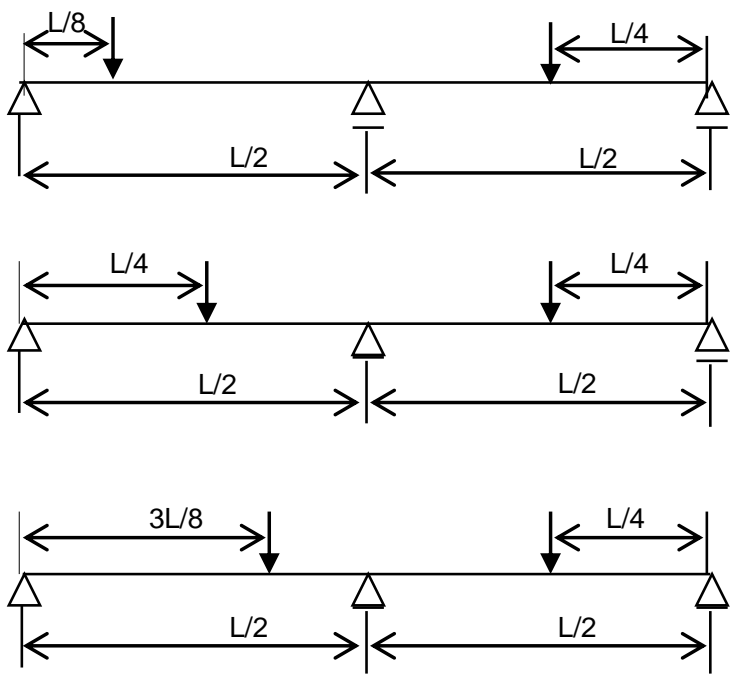

Gambar 2. Posisi pembebanan 
Besarnya defleksi diukur pada penampang batang yang berjarak $\mathrm{L} / 8=125$ $\mathrm{mm}, \mathrm{L} / 4=250 \mathrm{~mm}$ dan $3 \mathrm{~L} / 8=375 \mathrm{~mm}$ pada masing-masing bentangan untuk setiap perletakan beban sepanjang balok dan jenis bahan yang digunakan. Perletakan beban pada balok dilakukan dengan kombinasi seperti yang ditunjukkan gambar 2 .

\section{HASIL DAN PEMBAHASAN}

Dari hasil analisis yang dilakukan dengan metode tiga momen dan dari hasil pengujian dengan alat uji defleksi diperoleh nilai defleksi maksimum yang terjadi untuk masing-masing bahan dan letak pembebanan pada tiap-tiap bentangan seperti yang diperlihatkan pada tabel berikut:

Tabel 1. Defleksi untuk Baja Karbon

\begin{tabular}{|c|l|c|c|}
\hline $\begin{array}{c}\text { Posisi } \\
\text { Beban }\end{array}$ & $\begin{array}{c}\text { Jarak } \\
\text { Defleksi }\end{array}$ & $\begin{array}{c}\text { Metode } \\
\text { Tiga } \\
\text { Momen }\end{array}$ & Pengujian \\
\hline \multirow{2}{*}{1} & $2 \mathrm{~L} / 8$ & 0,000355 & 0,00010 \\
\cline { 2 - 4 } & $6 \mathrm{~L} / 8$ & 0,000487 & 0,00017 \\
\hline \multirow{2}{*}{2} & $2 \mathrm{~L} / 8$ & 0,000487 & 0,00016 \\
\cline { 2 - 4 } & $6 \mathrm{~L} / 8$ & 0,000487 & 0,00014 \\
\hline \multirow{2}{*}{3} & $2 \mathrm{~L} / 8$ & 0,000355 & 0,00011 \\
\cline { 2 - 4 } & $6 \mathrm{~L} / 8$ & 0,000487 & 0,00015 \\
\hline
\end{tabular}

Tabel 2. Defleksi untuk Kuningan

\begin{tabular}{|c|l|l|l|}
\hline $\begin{array}{c}\text { Posisi } \\
\text { Beban }\end{array}$ & $\begin{array}{l}\text { Jarak } \\
\text { Defleksi }\end{array}$ & $\begin{array}{l}\text { Metode } \\
\text { Tiga } \\
\text { Momen }\end{array}$ & Pengujian \\
\hline \multirow{2}{*}{1} & $2 \mathrm{~L} / 8$ & 0,000940 & 0,00021 \\
\cline { 2 - 4 } & $6 \mathrm{~L} / 8$ & 0,001290 & 0,00048 \\
\hline \multirow{2}{*}{2} & $2 \mathrm{~L} / 8$ & 0,001290 & 0,00042 \\
\cline { 2 - 4 } & $6 \mathrm{~L} / 8$ & 0,001290 & 0,00039 \\
\hline \multirow{2}{*}{3} & $2 \mathrm{~L} / 8$ & 0,000940 & 0,00019 \\
\cline { 2 - 4 } & $6 \mathrm{~L} / 8$ & 0,001290 & 0,00042 \\
\hline
\end{tabular}

Tabel 3. Defleksi untuk Alluminium

\begin{tabular}{|c|l|l|l|}
\hline $\begin{array}{c}\text { Posisi } \\
\text { Beban }\end{array}$ & $\begin{array}{l}\text { Jarak } \\
\text { Defleksi }\end{array}$ & $\begin{array}{l}\text { Metode } \\
\text { Tiga } \\
\text { Momen }\end{array}$ & Pengujian \\
\hline \multirow{2}{*}{1} & $2 \mathrm{~L} / 8$ & 0,000881 & 0,00027 \\
\cline { 2 - 4 } & $6 \mathrm{~L} / 8$ & 0,001250 & 0,00078 \\
\hline \multirow{2}{*}{2} & $2 \mathrm{~L} / 8$ & 0,001250 & 0,00055 \\
\cline { 2 - 4 } & $6 \mathrm{~L} / 8$ & 0,001250 & 0,00066 \\
\hline \multirow{2}{*}{3} & $2 \mathrm{~L} / 8$ & 0,000881 & 0,00023 \\
\cline { 2 - 4 } & $6 \mathrm{~L} / 8$ & 0,001250 & 0,00065 \\
\hline
\end{tabular}

\section{Pembahasan Grafik}

Dari hasil analisis terlihat bahwa defleksi terbesar terletak di titik tengah setiap bentangan baik analisis dengan metode tiga momen maupun hasil pengujian dengan alat uji defleksi. Pada setiap bentangan untuk semua jenis bahan terlihat bahwa pada letak pembebanan 2, defleksi bertambah dari tumpuan kiri sampai ke titik tengah bentangan dan kemudian berkurang sampai ke tumpuan kanan dimana pertambahan maupun penurunannya relatif seragam.

Untuk letak pembebanan 1 pola yang terlihat adalah pada jarak yang sama dari titik tengah bentangan, defleksi yang terjadi pada titik dekat perletakan beban akan lebih besar dibandingkan dengan defleksi yang terjadi pada titik yang lebih jauh dari perletakan beban, hal ini berlaku untuk semua jenis bahan. Untuk letak pembebanan 3 pola yang terlihat sama seperti yang terjadi pada letak pembebanan 1. Perubahan besar defleksi pada jarak tertentu hanya terjadi pada bentangan 1-2 sedangkan untuk bentangan 23 sama seperti letak pembebanan 2 untuk masing-masing bahan.Berikut diberikan grafik defleksi untuk setiap jenis bahan :

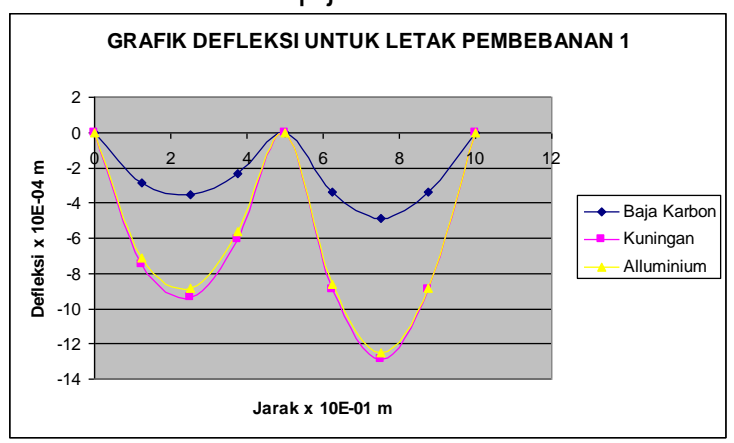

Gambar 3. Defleksi untuk letak pembebanan 1 GRAFIK DEFLEKSI UNTUK LETAK PEMBEBANAN 2

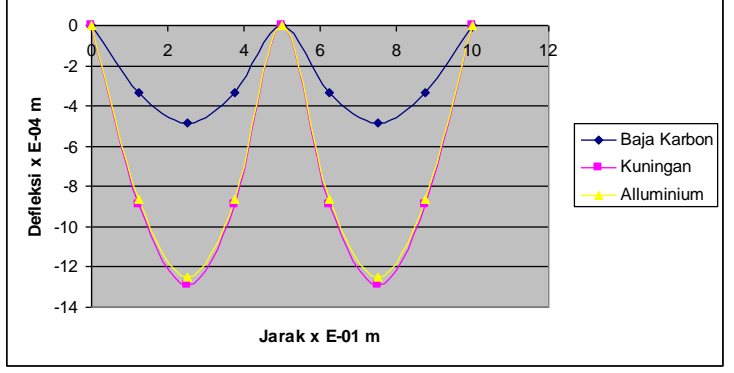

Gambar 4. Defleksi untuk letak pembebanan 2 


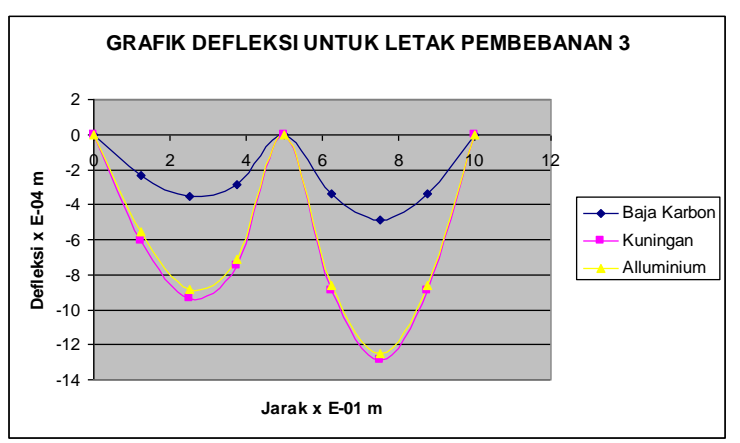

Gambar 4. Defleksi untuk letak pembebanan 3

Dari grafik di atas dapat dijelaskan bahwa besar defleksi sangat dipengaruhi oleh letak beban yang berkaitan dengan momen yang ditimbulkan yaitu semakin jauh letak beban dari tumpuan semakin besar momen, dan jenis material yang berkaitan dengan besar elastisitas bahan yaitu semakin besar nilai kekakuan bahan semakin kecil defleksi yang terjadi.

\section{KESIMPULAN}

1. Defleksi yang terjadi berdasarkan analisis metode tiga momen (teoritis) ternyata lebih besar dari defleksi berdasarkan hasil pengujian (eksperimen) dengan perbedaan masing-masing adalah :

- Baja Karbon,sebesar 2,45E-04 sampai 3,47E-04 meter

- Kuningan, sebesar 7,30E-04 sampai 9,00E-04 meter

- Alluminium, sebesar 4,70E-04 sampai 7,00E-04 meter

2. Letak beban sepanjang balok untuk tumpuan engsel -roll-roll sangat mempengaruhi defleksi yang terjadi, yang kisarannya untuk masing-masing bahan yakni ;

- Baja Karbon, antara 3,55E-04 sampai 4,87E-04 meter

- Kuningan, antara 9,40E-04 sampai 1,29E-03 meter

- Alluminium, antara 8,81E-04 sampai 1,25E-03 meter

\section{DAFTAR PUSTAKA}

[1] Timoshenko, 1950, Strength of Material, Elementary Theory and Problem, Part I, D Van Nostrand Company, Inc.Toronto,New York, London.

[2] Meriam dan Kraige, 1991, Statika, Penerbit Erlangga, Jakarta.

[3] Gere dan Timosenko, 1984, Mekanika Bahan, Jilid II, Terjemahan oleh Bambang Suryoatmono, 1996,Penerbit Erlangga, Jakarta.

[4] William and Sturgess, 1983, Schaum's Outline of Theory and Problems of Strength of Material, Second Edition, McGraw-Hill International Book Company, Singapore.

[5] Timoshenko and Goodier, 1970, Theory of Elasticity, Third Edition, Terjemahan oleh Darwin Sebayang, 1994, Penerbit Erlangga, Jakarta. 